\title{
The Efficiency of Provincial Medical Care Services in China
}

\author{
Tian Wang ${ }^{1, a}$ and Lei Chen ${ }^{2, b^{*}}$ \\ ${ }^{1}$ Wuhan Business University, Wuhan, Hubei 430056, China \\ ${ }^{2}$ Jianghan University, Wuhan, Hubei 430056, China \\ aTianwang28@126.com, 'lei.chen@jhun.edu.cn \\ * The Corresponding Author
}

\begin{abstract}
Keywords: Medical care services; Technical efficiency; Data envelopment analysis; Second-stage regression
\end{abstract}

\begin{abstract}
The last three decades evidenced the rapid growth of China's economy. Meanwhile, Chinese residents' health and medical conditions have been significantly improved. Based on the medical \& health data of 31 provincial districts in mainland China published by China Health Statistics Yearbook in 2015, we study the efficiency of medical and health services among residents in different provincial districts and the external factors influencing these medical efficiencies. We consider the average life expectancy and the perinatal survival rate as the two outputs of a region's health \& medical services, and the region's annual per capita medical expenditure, the number of health workers per one thousand residents, the number of hospital beds per one thousand residents as the three inputs of health \& medical services in the region. We use the output-oriented CRS data envelopment analysis model to analyze the efficiency of health \& medical services in various regions. The result shows that, among the 31 provincial districts in mainland China, only Anhui, Jiangxi, Hainan, and Xizang reach the efficiency of $100 \%$. The average efficiency among these 31 provincial districts is $85.1 \%$. We further use the second-stage linear regression analysis model to study the external causes of the variation in efficiency across regions. We find that the higher the proportion of health care workers other than practicing doctors or registered nurses, the higher the efficiency of medical \& health services in the region. At the same time, the longer the average length of hospital stay, the lower the efficiency of medical \& health services in the region. Finally, the proportion of sex among residents in a region has an impact on the efficiency of health care services -- the health care services in areas with more male residents are more efficient.
\end{abstract}

\section{Introduction}

From 1949 to 1978, the Peoples' Republic of China government provided free health care to all the workers who worked at the state-owned firms, which mostly located in urban area. Whereas in rural area, there were no free health care for farmers or hospitals, yet the so called "barefoot doctors" would provide very basic medical services to the local residents with minimum fees.

Starting from 1979, along with the economic reform in China, some county level community hospitals have been built up for people living in rural area, although they have to pay relatively high fees to get the services. While in urban area, more and more modern hospitals are in services for the residents. Therefore, in general people in China are getting better health services over the last 50 years.

However, these changes come with the cost of rapid increment of government expenditure on health care. Thus in late 1998, the central government announced the reform plan of health care system in China, and started implementing it in 2000. The foundational change according to the reform is that instead of government paying all the health care expenditure for workers in state-owned firms, government generates health insurance fund for all the employed workers in all kinds of firms. And the fund comes from the government, the firms, and the workers, where the firms pay most of the premium. 


\section{Literature Review}

Chow (2006) discussed the reform of health care reform in China and changes in health care institutions. He used the CLSY data to analyze both the demand and supply sides of health care in China. Then he evaluated the current health care system and showed that under such system the urban residents receive much better health services than rural residents. He thought one failure of the reform is that it failed to allow market force to operate in the supply of health care.

Guo and Wang (2002) reviewed the health care system in China for the past 50 years and pointed out the achievement and failures in past as well as the current difficulties and challenges. They thought the current problems of the health care system include (i) there are still a lot of people who don't have health insurance, especially in rural area; (ii) the health care expenditure keep increasing rapidly; (iii) the supply of health care services can't meet the rising demand of the health care services. They suggest the government invest more on health care services and provide basic health insurance to people in rural area.

Wang et al (2007) introduced the new reform of primary health care system announced by the government in 2006, and discussed the impartment role that family physicians could be in the new health care system. They also pointed out that "expensive to receive health care and inconvenient to access health care" have become two major complaints among Chinese people.

All the papers mentioned above used nation-wide data to show the challenge that current health care system faces due to the rapid increase of health care expenditure. In this paper, we apply the province level data to evaluate the efficiency in health care services in each province and explore what external factors would affect the variation on efficiency scores across provinces.

\section{Methodology}

In this paper, we apply the non-parametric DEA method to evaluate the efficiency. We first apply the output-oriented constant-returns-to-scale (CRS) DEA model to evaluate the technical efficiency (TE) of health care services in each province. Then we run a second-stage regression to investigate how TE can be influenced by external factors.

In DEA, we construct a benchmark technology from the observed input-output bundles of the firms in the sample. We then make the following four assumptions about the production technology (Ray 2004):

All actual observed input-output combinations are feasible;

The production possibility set is convex;

Inputs are freely disposable;

Outputs are freely disposable.

The linear programming (LP) form of the output-oriented CRS DEA model (CCR model) can be expressed as:

$$
\begin{gathered}
\max \phi \\
\text { s.t. } \sum_{j=1}^{N} \lambda_{j} y_{j} \geq \phi y_{t} ; \\
\sum_{j=1}^{N} \lambda_{j} x_{j}^{i} \leq x_{t}^{i} ;(i=1,2, \ldots, I) ; \\
\lambda_{j} \geq 0 ;(j=1,2, \ldots, N) .
\end{gathered}
$$

Where $\mathrm{I}$ is the number of inputs; $\mathrm{N}$ is total number of observations; $\mathrm{t}$ is one observation under evaluation among the $\mathrm{N}$ observations. The technical efficiency of observation $\mathrm{t}$ can be defined as: $=\frac{1}{\phi^{*}}$.

\section{Data and Result}

We apply the medical \& health data of 31 provincial regions in mainland China published by China Health Statistics Yearbook in 2015. We consider two outputs and three inputs. The two outputs are average life expectancy and the perinatal survival rate. The three inputs are annual per capita medical care expenditure, the number of health workers per one thousand residents, and the number 
of hospital beds per one thousand residents. The data and DEA efficiency scores are shown in Table 1.

Table 1 Input-Output data and DEA efficiency scores of each province

\begin{tabular}{|c|c|r|r|r|r|r|}
\hline Region & $\begin{array}{c}\text { perinatal } \\
\text { survival } \\
\text { rate (per } \\
\text { 1000) }\end{array}$ & $\begin{array}{c}\text { average life } \\
\text { expectancy } \\
\text { (in 2010) }\end{array}$ & $\begin{array}{c}\text { number of } \\
\text { health } \\
\text { workers } \\
\text { per 1000 } \\
\text { residents }\end{array}$ & $\begin{array}{c}\text { annual per } \\
\text { capita } \\
\text { medical } \\
\text { expense }\end{array}$ & $\begin{array}{c}\text { No. of } \\
\text { hospital } \\
\text { beds per } \\
\mathbf{1 0 0 0} \\
\text { residents }\end{array}$ & $\begin{array}{c}\text { CRS DEA } \\
\text { score }\end{array}$ \\
\hline Beijing & 995.95 & 80.18 & 9.91 & 6337 & 4.84 & 0.661 \\
\hline Tianjin & 992.81 & 78.89 & 5.6 & 3750 & 3.79 & 0.837 \\
\hline Hebei & 995.47 & 74.97 & 4.76 & 2027 & 3.9 & 0.932 \\
\hline Shanghai & 997.57 & 80.26 & 6.76 & 5170 & 4.61 & 0.705 \\
\hline Jiangsu & 996.72 & 76.63 & 5.76 & 2788 & 4.21 & 0.799 \\
\hline Zhejiang & 995.49 & 77.73 & 6.82 & 3114 & 3.89 & 0.821 \\
\hline Anhui & 995.59 & 75.08 & 4.41 & 2026 & 3.71 & 1 \\
\hline Fujian & 994.75 & 75.76 & 5.43 & 2213 & 3.72 & 0.921 \\
\hline Jiangxi & 996.71 & 74.33 & 4.43 & 1632 & 3.64 & 1 \\
\hline Shandong & 995.49 & 76.46 & 6.17 & 2307 & 4.89 & 0.756 \\
\hline Henan & 996.02 & 74.57 & 5.24 & 1792 & 4.19 & 0.914 \\
\hline Hubei & 995.36 & 74.87 & 5.77 & 2123 & 4.38 & 0.819 \\
\hline Hunan & 994.41 & 74.7 & 5.07 & 1953 & 4.32 & 0.876 \\
\hline Guangdong & 994.95 & 76.49 & 5.44 & 2366 & 3.35 & 0.977 \\
\hline Guangxi & 992.26 & 75.11 & 5.44 & 1796 & 3.6 & 0.992 \\
\hline Hainan & 994.21 & 76.3 & 5.6 & 2068 & 3.42 & 1 \\
\hline Chongqing & 995.68 & 75.7 & 5.16 & 2483 & 4.44 & 0.862 \\
\hline Sichuan & 995.47 & 74.75 & 5.55 & 2066 & 4.83 & 0.802 \\
\hline Guizhou & 994.56 & 71.1 & 4.85 & 1578 & 4 & 1 \\
\hline Yunnan & 992.75 & 69.54 & 4.43 & 1809 & 4.18 & 0.982 \\
\hline Xizang & 983.25 & 68.17 & 4.05 & 2366 & 2.72 & 1 \\
\hline Shaanxi & 995.47 & 74.68 & 6.69 & 2701 & 4.51 & 0.747 \\
\hline Gansu & 992.66 & 72.23 & 4.88 & 2007 & 4.36 & 0.89 \\
\hline Qinghai & 993.01 & 69.96 & 5.82 & 2813 & 4.54 & 0.728 \\
\hline Ningxia & 991.36 & 73.38 & 6.01 & 2569 & 4.29 & 0.773 \\
\hline Xinjiang & 985.73 & 72.35 & 6.68 & 2946 & 5.89 & 0.643 \\
\hline & & & & & & \\
\hline
\end{tabular}

\section{Second-stage Regression}

After we get the estimation of efficiency score for each province from DEA, we can include external factors and run a second-stage regression to investigate how health care services efficiency can be influenced by these external factors.

The linear regression model we choose is the following:

$$
E f f i=\beta_{0}+\beta_{1} \text { Days }+\beta_{2} \text { Sex }+\beta_{3} \text { Other }+e
$$

Where Effi is the efficiency score; Days is the average length of hospital stay; Sex is the ratio of male residents to female residents; Other is the proportion of health care workers other than practicing doctors or registered nurses.

The regression result is shown in Table 2 . 
Table 2 Regression result

\begin{tabular}{|c|c|c|c|}
\hline & Coefficients & $\begin{array}{c}\text { Standard } \\
\text { Error }\end{array}$ & t-ratio \\
\hline$\beta_{0}$ & 0.643 & 0.605 & 1.064 \\
\hline$\beta_{1}$ & -0.061 & 0.016 & $-3.782^{* * *}$ \\
\hline$\beta_{2}$ & 0.611 & 0.530 & 1.152 \\
\hline$\beta_{3}$ & 0.635 & 0.317 & $2.003 * *$ \\
\hline
\end{tabular}

\section{Conclusion}

The result shows that the higher the proportion of health care workers other than practicing doctors or registered nurses, the higher the efficiency of medical $\&$ health services in the region. At the same time, the longer the average length of hospital stay, the lower the efficiency of medical \& health services in the region. Finally, the proportion of sex among residents in a region has an impact on the efficiency of health care services -- the health care services in areas with more male residents are more efficient.

\section{References}

[1] Chow, Gregory C., An Economic Analysis of Health Care in China, CEPS Working Paper, No. 132, Princeton University. (2006)

[2] Guo, Youde and Huanhua Wang, A Reconsideration of the Health Care Insurance Reform in China, Population and Economics, additional issue, Oct. 2002, pages 159-161. (2002)

[3] Wang, Jie et al, Primary Care Reform in the Peoples' Republic of China: Implications for Training Family Physicians for the World's Largest Country, Regional Reports - Asia, 39(9):639-643. (2007)

[4] Ramesh, M., Xun Wu, and A lex Jingwei He, Health Governance and Healthcare Reforms in China, Health Policy and Planning, 29(6):663-672. (2014)

[5] Fang, Hai, Qingyue Meng, and John A. Rizzo, Do Different Health Insurance Plans in China Create Disparities in Health Care Utilization and Expenditures? International Journal of Applied Economics, 11(1):1-18. (2014) 